\title{
Design of a Framework for Professional Development Programs for Teachers in the Use of Interactive Touch Screen
}

Perera, K.G.S.K., Wijesundara, M. \& Siriwardhena, I. susil.p@sliit.lk, malitha.w@sliit.lk, indrani.s@sliit.lk

School of Natural Science, Faculty of Humanities and Sciences, SLIIT, Malabe, Sri Lanka

\begin{abstract}
Interactive Touch Screens (ITSs) are distributed in selected schools in Sri Lanka. Although, in these schools, selected teachers are trained on the use of the ITS, comprehensive training on the instructional strategies of ITS is yet to be provided. The objective of the study was to design and develop a framework for professional development programme (PDP) for teachers on the use of ITS. The sample of 31 teachers of an educational zone in the Colombo district was selected to test the methodology. Instruments for quantitative data collection were six scales and to collect qualitative data open-ended questions were used. Design Based Research (DBR) approach was made to evaluate the new methodology. DBR approach is characterized by analysis of the problem domain, design of the solution (intervention), iterative cycles of testing and refining the solution and finally reflecting on the whole process to arrive at design principles and inventing the solution. Intervention of this study was in terms of two professional development programmes on the integration of ITS in instruction. The results of the first intervention are presented in this paper. Analysis of data formed the feedback to design the revised PDP. The results of the study are the feedback to the proposed revisions to the next PDP. The feedback was to increase the time allocation of the PDP, provide more hands-on experience, demonstrate ITS-based instructional strategies related to different subject areas and conduct separate PDPs for non-ICT teachers.
\end{abstract}

Keywords: Authoring software, Design-based research, Interactive touch screen, Instructional design.

\section{Introduction}

Interactive Touch Screen (ITS) is a digital device that enables users to make vivid visual presentations and manipulate onscreen objects through digital touchscreen interactions. Modern ITS has an embedded computer with an operating system so that software could be run on the ITS itself in addition to receipt of visuals from a separate computer via cable connectivity. Further, the Internet can also be directly connected to the ITS using the embedded computer (Lefebvre et al., 2016). At present ITSs are distributed in the school system in Sri Lanka. In order to make maximum use of ITSs, teachers should know how to integrate them in their instructional process. This requirement could be well addressed through professional development programs (PDP). Rather than proposing a design of one PDP, it is more effective to design a framework for PDPs on the use of ITS so that using the framework, a PDP suitable for a given context could be 
developed by any authority expecting to conduct PDPs in this respect.

Studies on the use of ITS in the Sri Lankan school sector are not available due to the recency of its introduction. Therefore, a study into the current use of ITSs and proposition of a framework for PDPs to ensure productive use of them could ensure the teachers and students the benefit of the vast cost incurred in the acquisition of these hardware thereby making it as a worthwhile investment in the school system.

Integration is explicitly different from mere operational use of hardware and software, and it is assumed to be a part of teachers' general understanding (Lloyd, 2005) while lack of skills in designing ICT based instruction could be a disadvantage despite the presence of ICT resources and positive attitude towards ICT (Tsai \& Chai, 2012).

From the cognitive point of view, for teachers to become effective ICT integrators, Mishra and Koehler (2006) have formulated a framework known as Technological Pedagogical Content Knowledge(TPACK). The TPACK framework which provides useful guidance for teachers to become effective ICT integrators, describes how three broad knowledge bases, knowledge of technology (TK), knowledge of pedagogy (PK) and knowledge of content (CK), interact to create several forms of new knowledge. These forms of knowledge are identified as Technological Pedagogical Knowledge (TPK), Technological Content Knowledge (TCK) and Pedagogical Content Knowledge (PCK). Interaction of TPK, TCK and PCK results in TPACK (Mishra \& Koehler, 2006).
Technological Pedagogical Knowledge (TPK) refers as the relevant technical knowledge required to implement instructional designs, but this includes tools used for evaluation and maintaining of records about learning and also refers to the "Knowledge about the manner in which technology and content are reciprocally related" (Mishra \& Koehler, 2006, p. 1028). It is about how to represent subject matter using appropriate technology. PCK refers to the subject knowledge and relevant instructional method which should be possessed by a teacher.

How ITS could be used to develop TPK of teachers is a combination of hardware and software associated with ITS and relevant pedagogical knowledge. Numerous studies have shown that use of ITSs improves learning processes, specifically where the integration between the teacher's instruction style and the ITSs' potential enable meaningful instruction (Betcher \& Lee, 2009). Students have also reported that the use of the ITS enhances motivation to learn, raises the level of concentration, improves behaviour, and enhances learning because it is 'fun' and innovative (British Educational Communications and Technology Agency, 2008; Cogill, 2002; Hall \& Higgins, 2005; Lioyd, 2005; Morgan, 2008; Thompson \& Flecknoe, 2003).

\section{Objective of the study}

On view of the above, the objectives of this study are to -

- Analyse the current usage of ITS of teachers in the school system; 
- Design and develop a professional development program (PDP) for teachers on the use of ITS;

- Implement the PDP and evaluate the effect on the teachers; and

- Provide recommendation for decision makers in education.

\section{Materials and Methods}

\section{Research methodology}

The research approach was Designed-Based Research (DBR) with mixed mode design where both quantitative and qualitative data were collected in the research process. Figure 1 illustrates the phases of DBR.

DBR is defined as " a systematic but flexible methodology aimed to improve educational practices through iterative analysis, design, development, and implementation, based on collaboration among researchers and practitioners in real-world settings, and leading to contextually-sensitive design principles and theories" (Wang \& Hannafin ,2005, p6). Accordingly, it is an iterative process leading to building theories and principles in a particular setting via analysis of the problematic situation, suggesting a solution, materializing the solution and finally implementation with actually attempting to solve the problem. The process is not linear but follows a cyclic pattern moving back from reflection on the implementation to analysis.

\section{Phase 1 of DBR - Analysis of the problem}

The problem domain was analysed via a comprehensive literature review on the issues in the use of ITS worldwide, and through discussions conducted with two Directors of
ICT, one of Homagama and the other of Sri Jayawardhenapura educational zones on the current situation of the distribution and the use of ITS in the school system. One school visit was performed in order to investigate into the ground situation of the ITS integration in the instructional process.

\section{Phase 2 of DBR- Development of Solution}

The PDP, two day workshop of six hours each, was designed as per the findings of the literature review, discussion with the Directors and the initial observations made in the school visit. The PDP was implemented for 31 selected teachers of the Homagama educational zone. In this PDP, TK,TPK, TCK and TPACK were addressed.

\section{Phase 3 of DBR - Iterative Cycles of Testing and Refinement of the Solution}

The PDP conducted was the first cycle of the entire study. This is the implementation of the developed solution.

\section{Phase 4 of DBR -Reflection to refine Design Principles}

The outcomes of the PDP were reflected upon as follows to ascertain refinements necessary to redesign and redevelop the next PDP. Analysis of the problem domain through the literature review revealed that globally there is a lack of sound theoretical base for integration of ITS in instructional process and the need to address aspects in TPACK framework and the potential of ITS for creative lesson plans. Analysis of the problem domain through initial interviews and the school visit revealed that teachers, who were trained on ITS, could operate the hardware but lacked 
in instructional strategies to integrate ITS in instruction.

On the first day, a session was conducted to explain the functionality of the ITS, demonstration of how to integrate ITS in instructional process and introduction to the use of Google Classroom. In the process, required TPK was addressed. Next,introduction to recording of a lecture session using OBS software was conducted to address TCK required for effective integration of technology in instruction. The session was not conducted in a computer laboratory hence it was not possible for the participants to acquire hands-on experience with Google Classroom and screen recording using OBS. However, it was allowed the teachers to take turns on experiencing the functionality of the ITS. In this session, participants were introduced to a web-based interactive facility on multiple choice questions (MCQ) known as Kahoot (www.kahoot.com). The ITS was used to display the MCQs to the participants and answering the questions was effected through their smart phones. How to create a MCQ activity using Kahoot was also demonstrated.

\section{Primary data collection}

The necessary data was obtained via six structured questionnaires : Q1-Q6. On the first day, before the beginning of the session on ITS, a questionnaire (Q1) was administrated to the participants to capture the demographic data of the participants and a scale (Q2) to measure participants basic ICT skills required to follow the session (ICT readiness). This component of the session was meant to address TPK requirement in instructional process with respect to the use of ITS.
Another scale (Q3) was also administered at the end of the session to measure the perceived impact of the session on the participants. At the end of the session, participants' free observations were also collected as to effectiveness of the sessions and suggestions for modifications in future PDPs. This was in the form of self-reporting of the impact they had received.

On the second day, before the beginning of the session on PowerPoint-based authoring software, a scale (Q4) was administered to the participants to measure the participants' initial skills (PowerPoint readiness) in the use of PowerPoint in development of lesson material. The session commenced with a demonstration of interactive multimediabased educational software in order to explain the instructional design features and the good practices of educational software, addressing the TPACK requirement for a productive integration of technology in instruction. Next, a session on the use of a PowerPoint-based authoring software for the development of interactive lessons were conducted. As the teachers had not brought laptops, they were allowed to attempt the tools of the software on the ITS itself, taking turns. In this part of the session TPK requirement was addressed.

At the end of this session a scale (Q5) was administered to measure the perceived impact of the session on the participants' use of PowerPoint-based authoring software in instructional material development.

Finally, at the end of the PDP (i.e. end of the second day) a scale (Q6) was administered to measure the perceived total impact on the participants in the use of ITS, with respect 
to both sessions on day 1 and day 2 , in their instructional process. This was in the form of self-reporting of the impact they had received. At the end of the session, participants' free observations were also collected as to effectiveness of the session and suggestions for modifications in future PDPs.

\section{Data analysis}

The scales Q2, Q3, Q4, Q5 and Q6 were 5 point Likert scale questionnaires with following values for each option. Strongly agree (5), agree (4), neutral (3), disagree(2) and strongly disagree (1). For each scale, total score for each individual participant was calculated and converted to percentage scale. The selections made by the participants in the scales in Q2 to Q6 were translated into values as indicated by Brown (2011) and then basic statistics: mean and SD were computed for comparison purposes.

Two separate scatter diagrams, IT readiness vs. impact of session 1 (Day 1) on both ICT participants and non-ICT participants were plotted. Another two separate scatter diagrams, PowerPoint readiness vs. impact of session 2 (Day 2), one on ICT participants and another on non-ICT participants were also plotted. Furthermore, two correlation coefficients were separately calculated: (1) between ICT readiness and impact of session 1 on ICT participants, and (2) between ICT readiness and impact of session 1 on non-ICT participants, to test whether there was any significance correlation between the relevant variable pairs. ICT participants were the teachers who teach ICT at school and non-ICT participants were those who do not teach ICT at school.

\section{Results and Discussion Demographic information}

Analysis of the responses to Q1 revealed that out of 31 participants $32 \%$ (10) were ICT teachers and $68 \%$ (21) were non-ICT teachers. However, $84 \%$ (26) had some form of ICT training while the remaining $16 \%$ were not formally exposed to ICT. Furthermore, 45\% (14) were graduates and 55\% (17) were nongraduates and their age varied from 26 years to 50 years.

\section{Analysis of ICT skills - Q2}

The ICT readiness was calculated based on the responses given to all the items in the scale Q2. The contributing factors for the ICT readiness are hardware knowledge, software knowledge, Internet knowledge and exposure to ITS. Statistics of these factors were calculated by appropriately grouping items on the scale Q2 and considering the responses to each group of items separately. The mean and standard deviation of the both non-ICT readiness and ICT participants for each contributing factors are separately given on the $\%$ scale in the Table 1. 
Table 1.

Basic statistics of the marks derived from Q2 for non-ICT and ICT participants.

\begin{tabular}{lll}
\hline \multirow{2}{*}{ Variable } & \multicolumn{2}{c}{ Mean (SD) } \\
\cline { 2 - 3 } & Non -ICT & ICT \\
\hline Hardware knowledge & $74(21)$ & $92(13)$ \\
\hline Software knowledge & $79(21)$ & $98(2)$ \\
\hline Internet knowledge & $87(18)$ & $100(0)$ \\
\hline Exposure to ITS & $26(35)$ & $12(10)$ \\
\hline ICT readiness & $70(17)$ & $82(7)$ \\
\hline
\end{tabular}

Parentheses indicate the SD

Results in Table1 indicate that ICT readiness of the non-ICT participants were strong enough for successful completion of the session 1 because their perceived hardware knowledge, software knowledge and Internet knowledge have returned high values ( $\geq 70$ each).The low marks returned for exposure ITS is not considered as a barrier but could be considered as a preferable condition. Results also indicate that ICT readiness of the ICT participants were strong enough for successful completion of the session 1 because their perceived hardware knowledge, software knowledge and Internet knowledge have returned high values ( $>90$ each) which is obvious expectation as they are ICT teachers themselves. The low marks returned for exposure ITS is not considered as a barrier but could be considered as a preferable condition. The ICT participants got higher marks and lower SD for all five variables than that of for non-ICT participants.

\section{Analysis of the perceived impact - Q3}

Results of the analysis of the responses by both non-ICT and the ICT participants to scale Q3 are provided in Table 2.

Table 2.

\section{Basic statistics of marks derived from Q3 for} ICT participants.

Mean(SD)

\begin{tabular}{|c|c|c|}
\hline \multirow{2}{*}{ Variable } & & \\
\hline & $\begin{array}{l}\text { Non- } \\
\text { ICT }\end{array}$ & $\mathrm{ICT}$ \\
\hline $\begin{array}{l}\text { Positive feeling toward } \\
\text { the session }\end{array}$ & $84(13)$ & $85(13)$ \\
\hline $\begin{array}{l}\text { Effectiveness of the } \\
\text { session }\end{array}$ & $81(15)$ & $84(14)$ \\
\hline Motivation to use ITS & $82(17)$ & $83(14)$ \\
\hline $\begin{array}{l}\text { Technical } \\
\text { improvement }\end{array}$ & $81(14)$ & $83(15)$ \\
\hline Training conditions & $92(9)$ & $93(8)$ \\
\hline Total impact & $84(11)$ & $86(11)$ \\
\hline
\end{tabular}

Parentheses indicate the SD

The total impact was calculated based on the responses given to all items in the scale Q3. It can be seen that there is no significant difference of the marks between ICT and non ICT users for all five aspects. The contributing factors for the total impact were positive feeling toward the session, effectiveness of the session, motivation to use ITS, technical improvement of the participants and training conditions provided. Statistics for these factors were calculated by appropriately grouping the items on the scale Q3 and considering the responses 
to each group of items separately. The mean and standard deviation of the total impact and its contributing factors are separately given on the $\%$ scale in the Table 2 . Results in Table 2 indicate that the participation in the ITS session has had a tremendous impact on the ICT participants as all five contributing factors and total impact have high marks $(>80)$ and low variance. Results in Table 2 also indicate that the participation in the ITS session has had a tremendous impact on the non-ICT participants as all five contributing factors and total impact have high marks $(>80)$ and low variance.

\section{Analysis of qualitative responses}

As improvements for future PDPs, participants suggested about preference on separate PDPs for non-ICT teachers. In that case, they stressed, it would be possible for the session to proceed at a slower rate to match their speed of learning. In this case one participant stated, "...when the lecturer asked whether the participants have understood what has been explained, ICT teachers were quick to respond that they have whereas I as a non-ICT teacher have not". More hands-on experience was requested and preferably sessions must be conducted at school level so that issues with respect to a particular version of ITS could be addressed. This was evident from the statement made by one of the participants as "The ITS given to my school is little different from the one was used in the session. Therefore, issues with respect to that were not explained in this session".

"I do not know how to create or edit videos that could be downloaded from YouTube. If I have that knowledge, I could make much better lessons." This statement gives rise to the need of practical sessions on multimedia processing in next PDP. How to connect laptops with ITS via a network was another request as per the statement "In my school the ITS is placed in the computer lab where the computers are networked. So, it is useful for us to know how the ITS could be connected with computers to see students responses to questions on ITS". According to the request "Use of ITS in teaching/learning process is a new modality. I am still not very much clear about how exactly a lesson could be conducted using ITS", this complain should be addressed by demonstrating sample lessons on ITS in the next PDP. "I have never attempted to use ITS in my lessons at school. Therefore, I will run into real practical problems while I am using ITS. Therefore, if the lecturer visits my school and look into such issues, I will be able to continue to use ITS with confidence". Accordingly, school visits are a must before upgrading and redesign the next PDP in order to solve practical problems the teachers would encounter in their actual practice.

One teacher complained "I was a little late to attend the session today. As I missed the first part of the session it was difficult for me to understand the rest of the session". Another participant complained "What I learned today was not with hands-on experience. Therefore, I might forget what I have learned today once I returned to my school" So, based on these complaints, video recording of the sessions and making it available to the teachers would help them revise their knowledge on the ITS use and it would be beneficial for those who have missed the sessions fully or partly. On the other hand, it would be a feedback to design and implement the next PDP. 


\section{Relationship between ICT readiness and session impact}

The scatter plots between ICT readiness and session impact of ICT participants and nonICT participants are shown in Fig. 2 and Fig. 3 respectively. Both graphs show a weak linear relationship between the two variables. In fact, this was confirmed as the correlation coefficient in both cases were not significantly different from zero $(\mathrm{p}>5 \%)$.

Figure 2.

Scatter plot between ICT readiness of the participants (ICT teachers) and impact of the session 1

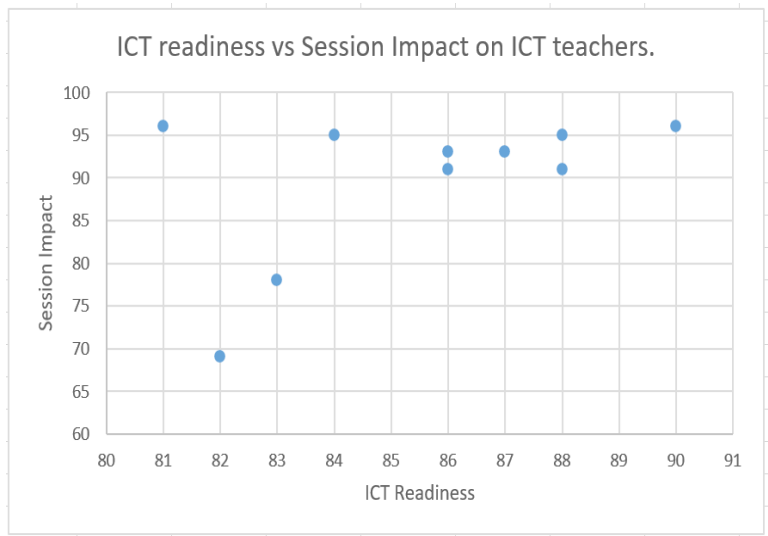

Figure 3.

Scatter plot between ICT readiness of the participants (Non-ICT teachers) vs. Impact of the session 1

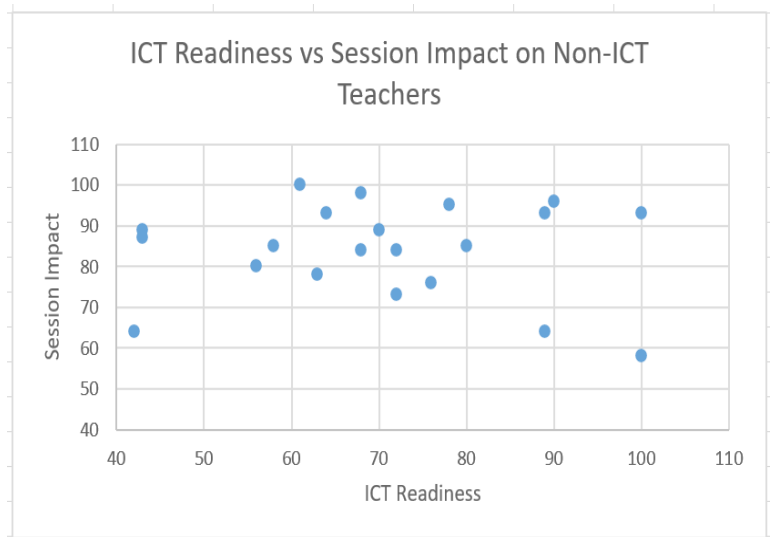

Analysis of the session on PowerPointbased authoring software - Q4

Table 3.

Basic statistics of marks derived from $Q 4$

for ICT teachers.

\begin{tabular}{lcc}
\hline \multirow{1}{*}{ Variable } & \multicolumn{2}{c}{ Mean (SD) } \\
\cline { 2 - 3 } & \multicolumn{1}{c}{ ICT } & ICT \\
\hline $\begin{array}{l}\text { Basic PowerPoint } \\
\text { skills }\end{array}$ & $74(23)$ & $92(11)$ \\
\hline $\begin{array}{l}\text { Advanced PowerPoint } \\
\text { skills }\end{array}$ & $52(13)$ & $72(21)$ \\
\hline $\begin{array}{l}\text { Teacher-centered } \\
\text { use of PowerPoint in } \\
\text { instruction }\end{array}$ & $67(31)$ & $70(29)$ \\
\hline $\begin{array}{l}\text { Student-centered use } \\
\text { of PowerPoint in } \\
\text { instruction }\end{array}$ & $47(26)$ & $67(31)$ \\
\hline $\begin{array}{l}\text { Total PowerPoint } \\
\text { readiness }\end{array}$ & $62(16)$ & $81(13)$ \\
\hline
\end{tabular}

Table 3 gives the summary statistics of the administering of Q4 on the participants. Total PowerPoint readiness was the combined effect of the contributing effects i.e. basic PowerPoint skills, advanced PowerPoint skills, use of PowerPoint in teacher-centered instruction and use of PowerPoint in teachercentered instruction. In the scale (Q4), separate items from the scale were allocated to measure these contributing factors. It was obvious that as they are ICT teachers, they have scored high on the scale and very well prepared for the session 2 . 
As indicated in the Table 3, ICT participants' PowerPoint readiness was strong enough to complete the session successfully. However, their use of PowerPoint in their instructional process (either teacher-centered or studentcentered) needs improvement. The Table 3 also summarizes the results of the administering of Q4 on the participants who were non-ICT teachers. It is clear that, although their basic PowerPoint skills are strong their advanced skills are average. Their use of PowerPoint in teacher-centered mode of instruction is satisfactory but their PowerPoint use in the student-centered mode is rather poor hence needs improvement. The total PowerPoint readiness for the session is acceptable as it was $62 \%$.

Analysis of perceived impact - Q5

Table 4.

Basic statistics of marks derived from Q5.

\begin{tabular}{lll}
\hline \multirow{2}{*}{ Variable } & \multicolumn{2}{c}{ Mean (SD) } \\
\cline { 2 - 3 } & $\begin{array}{l}\text { Non- } \\
\text { ICT }\end{array}$ & ICT \\
\hline $\begin{array}{l}\text { Positive feeling toward } \\
\text { the session }\end{array}$ & $88(11)$ & $95(9)$ \\
\hline $\begin{array}{l}\text { Effectiveness of the } \\
\text { session }\end{array}$ & $90(9)$ & $88(10)$ \\
\hline Motivation to use ITS & $90(9)$ & $85(9)$ \\
\hline $\begin{array}{l}\text { Technical improvement } \\
\text { Training conditions }\end{array}$ & $99(12)$ & $84(10)$ \\
\hline Total impact & $90(9)$ & $89(6)$ \\
\hline
\end{tabular}

Table 4 summarizes the results of administering of the scale Q5 on non-ICT participants and ICT participants. The total impact is the combined effect of the factors positive feeling toward the session, effectiveness of the session, motivation to use ITS, technical improvement in the participants and training conditions. In both cases the values of the contributing factors and the combined effect are very high $(>84)$ and report a small dispersion (low SD in each case) indicating vast majority has high values for each contributing factors. This is evidence to conclude that the session has had a very strong effect on the participants.

\section{Correlation between PowerPoint readiness and session effect}

\section{Figure 4.}

Scatter plot between PowerPoint readiness of the participants (ICT teachers) and Impact of the session 2.

PowerPoint Readiness vs Impact of the Session 2 on ICT Teachers

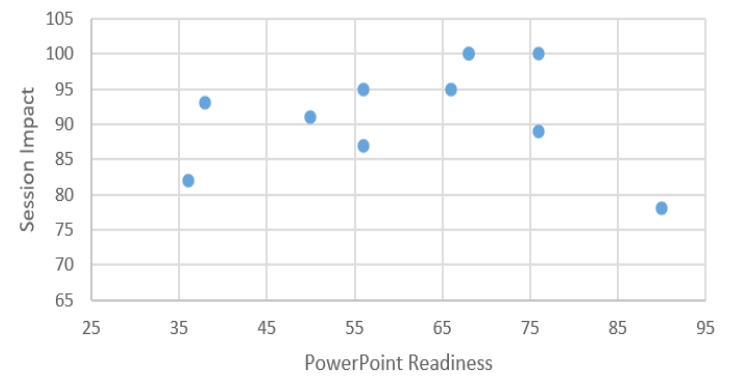

Figure 5.

Scatter plot between PowerPoint readiness of the participants (Non-ICT teachers) and Impact of the session 2

\section{PowerPoint Readiness vs. Session Impact on non-} ICT teachers

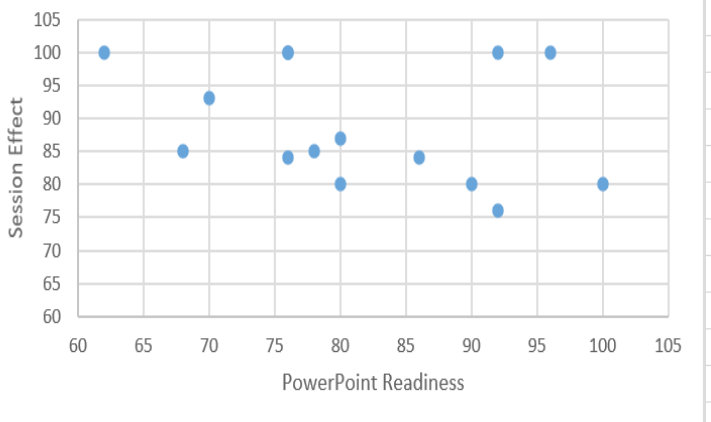


The two scatter plots shown in Figure 4 and Fig. 5 indicate that there is no significant linear relationship between the two variables for both ICT teachers as well as non-ICT teachers, and this was confirmed by the non significant correlation in both cases.

\section{Results from qualitative data}

The analysis of qualitative data collected on the impact of session 2 on the participants revealed that the session was successful but more hands-on experience was required. "Although this software appears useful, I need a lot of practice to become a good user because I am not a ICT teacher." Another participant suggested "This software must be demonstrated while I am having hands-on experience. Therefore, this lesson should be conducted in a computer lab". They stressed that the sessions to follow should be conducted in a ICT lab, preferably in their own schools, where they could get hands-on experience so that they have the opportunity to make use of the demonstrated software to develop material and be tested for the effectiveness. On the other hand, the problems they may encounter in trying out the software could be resolved immediately to continue with the development of material.

One comment was "The activities provided in the software was limited to MCQs, fill-in the blanks and drag and drops. It will be useful if more different activities are added to this software". Another suggestion was "I wish I have the choice to decide number of options on MCQs" and one further added "It is useful if I can change the number of drag and drops in the mapping exercise". "It will be very helpful if another session is conducted for us to present lessons developed using this software and instruct how to improve on them", was another request. They had suggested to upgrade the software with more instructional strategies, more hands-on sessions and content development sessions. Further they requested to conduct separate sessions for teachers who teach the same subject, "In this session, teachers are taken from different subjects. Therefore, it is difficult to address lesson development according to a particular subject. I wish the separate sessions to be conducted for different subject ". Another request was to video record a whole session for the benefit of those who would have missed the session and for revision purposes. Participants believed that the duration of PDP should be increased up to at least five days, "Two days are not enough to understand this software. Therefore, please increase the PDP to at least five days'.

Analysis of perceived total impact - Q6

Table 5.

Basic statistics of marks derived from Q6 for ICT teachers.

Mean (SD)

Variable

$\begin{array}{ll}\text { Non- } & \text { ICT } \\ \text { ICT }\end{array}$

Facilitation of teaching $\quad 86(10) 91(10)$

Facilitation of learning $\quad 83(9) \quad 95(9)$

Opportunity for a variety of instructional strategies

Improvement of students' 80 (10) 93 (10) active participation 


\section{Table 5 (Continued)}

\begin{tabular}{lcc}
$\begin{array}{l}\text { Promotion of students' } \\
\text { collaboration }\end{array}$ & $82(7)$ & $97(7)$ \\
\hline $\begin{array}{l}\text { Entertainment quality of } \\
\text { ITS }\end{array}$ & $80(12)$ & $92(12)$ \\
\hline $\begin{array}{l}\text { ITS ability to replace } \\
\text { blackboard }\end{array}$ & $75(23)$ & $64(23)$ \\
\hline $\begin{array}{l}\text { Total impact } \\
82(8)\end{array}$ & $82(10)$
\end{tabular}

Table 5 summarizes the result obtained by administering the scale Q6 on ICT participants. The construct measured by this scale was the perception of the participants as to the efficacy of ITS in the instructional process. The total impact was the combined effect of facilitation of teaching due to the use of ITS, facilitation of learning, opportunity offered by ITS for a variety of instructional strategies, improvement of students' active participation, promotion of students collaboration, entertainment quality of ITS and ITS ability to replace the blackboard. Each of these aspects was formed by aggregating several relevant items of Q6.

Analysis of results on administration of scale Q6 in terms of its different aspects as indicated in the Table 5 highlights several motive factors for teachers to use ITS in their instructional process. It is evident from the high values in the belief that ITS facilitates teaching, availability of a variety of instructional strategies, improvement of students' participation, collaboration among students and entertainment nature of ITS. The small standard deviation of each aspect implies a congruence in agreement of the participants to the high mean values. Although the agreement with that ITS could substitute the blackboard was high the variation of the opinion was also large. Thus it confirmed that ICT teachers also believe that ITS is useful as an alternative but not as a replacement of the blackboard.

Small standard deviations indicate that for a given aspect, majority of participants have similar values. Although the mean values of contributing factors (aspects) to the total impact are not as large as those in the case of ICT participants, strength of each contributing factors are considerably high indicating nonICT teachers are also highly motivated to use ITS in their instructional process. The opinion on ability of ITS to replace the blackboard is higher than that of ICT teachers, but relatively high standard deviation indicates less congruence in their opinion.

\section{Conclusions and Suggestions Conclusions}

Teachers are highly motivated to use ITS in their instructional process. In the design of PDP on ITS use in instruction both technical and instructional aspects have to be covered to address TPACK requirements to integrate ITS in instruction. It has been a major concern of the participants that length of each session, on ITS and authoring software, needs to be increased beyond one day. Although significant correlation was not found between teachers ICT knowledge and impact they had by the sessions held, separate PDPs should be conducted for ICT and non-ICT teachers, since majority of them requested so.

Furthermore, separate PDPs for each subject areas in school curriculum are preferred. It is not essential to demand a high initial ICT 
knowledge and skill from the participants although it is desirable. Demonstration of sample lessons based on a variety of disciplines on how to integrate ITS in the instructional process should be included in the future PDPs. More hands-on learning experiences should be provided in the use of OBS and Google Classroom. It is also recommended similar studies to be carried out under difference conditions and data should statistically analyzed to avoid subjectivity.

\section{Suggestions}

Practical sessions should be organized on how to set interaction between ITS and participants' computers via a wireless network, and multimedia processing. Video recording of future sessions should be carried out and made available to teachers. School visits must be made in order to observe participated teachers ITS integration in order to collect feedback for futures PDPs. Finally, sound training conditions could also be a motivation factor for participation in PDPs.

\section{Figure 1.}

Four phases of the DBR (Amiel \& Reeves, 2008, p. 34)

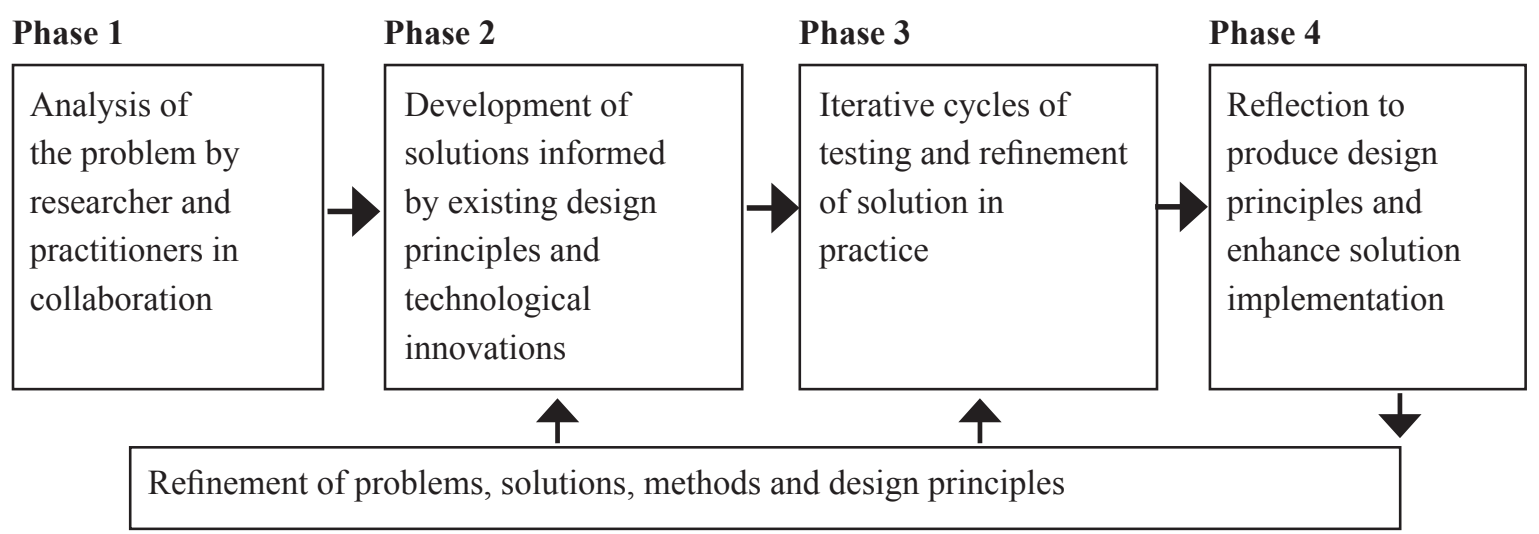

\section{References}

Amiel, T.\& Reeves, T.C.(2008). Design-based research and educational technology: Rethinking technology and the research agenda. Educational Technology \& Society, 11(4),29-40.Retrievedfrom https://www.researchgate.net/ publication/220374789_DesignBased_Research_and_Educational_ Technology_Rethinking_Technology_ and_the_Research_Agenda.
Betcher, C., \& Lee, M. (2009). The interactive whiteboard revolution - Teaching with IWBs. Victoria, Australia: ACER Press.

British Educational Communications and Technology Agency. (2008 July). Harnessing technology schools survey 2007: Analysis and key findings. Retrieved from https:// dera.ioe.ac.uk/1552/2/becta_2007 htschoolssurvey_report.pdf. 
Brown, J.D. (2011). Likert items and scales of measurement?.SHIKEN: JALT Testing \& Evaluation SIG Newsletter. 15(1) 10-14. Retrieved from https://hosted. jalt.org/test/PDF/Brown34.pdf.

Cogill, J. (2002). How is the interactive whiteboard being used in the primary school and how does this affect teachers and teaching? Retrieved from http://juliecogill.com/IFS_Interactive_ whiteboards_in_the_primary_school. pdf.

Hall, I., \& Higgins, S. (2005). Primary school students' perceptions of interactive whiteboards. Journal of Computer Assisted Learning, 21, 102-117.

Lefebvre, S., Samson, G., Gareau, A. \&Brouillette, N. (2016). TPACK in Elementary and High School Teachers' Self-reported Classroom Practices with the Interactive Whiteboard (IWB). Canadian Journal of Learning and Technology,42(5), 1-17. Retrieved from https://www.cjlt.ca/index.php/ cjlt/article/view/27521/20228.

Lloyd, M. (2005). Towards a definition of the integration of ICT in the classroom. Paper presented at the AARE'05 Education Research Creative Dissent: Constructive SolutionsConference. Retrievedfrom https://www.aare.edu. $\mathrm{au} /$ data/publications/2005/1lo05120. pdf.

Mishra, P., \& Koehler, M. J. (2006). Technological pedagogical content knowledge: A framework for teacher knowledge. Teachers College Record, 108(6),1017-1054. Retrieved from http://one2oneheights.pbworks.com/f/ MISHRA_PUNYA.pdf.

Morgan, G. L. (2008). Improving student engagement: Use of the interactive whiteboard as an instructional tool to improve engagement and behavior in the junior high school classroom (Doctoral dissertation).Retrieved from http://digitalcommons.liberty.edu.

Thompson, J., \&Flecknoe, M. (2003). Raising attainment with an interactive whiteboard in Key Stage 2. Management in Education, 17(3), 29-33.

Tsai, C.C., Chai, C.S. (2012). The "third"order barrier for technologyintegration instruction: Implications for teacher education. Australasian Journal of Educational Technology, 28(6),1051211060. Retrieved from http://ascilite.org.au/ajet/ajet28/tsai-cc. html.

Wang, F., \&Hannafin, M. J. (2005). Designased research and technologyenhanced learning environments. Educational Technology, Research and Development, 53(4), 5-23. Retrieved from https://www.researchgate.net/ publication/225626676_Design-based_ research_and_technologyenhanced_ learning_environments_Educational_ Technology_Research_and_ Development_534_5-23. 